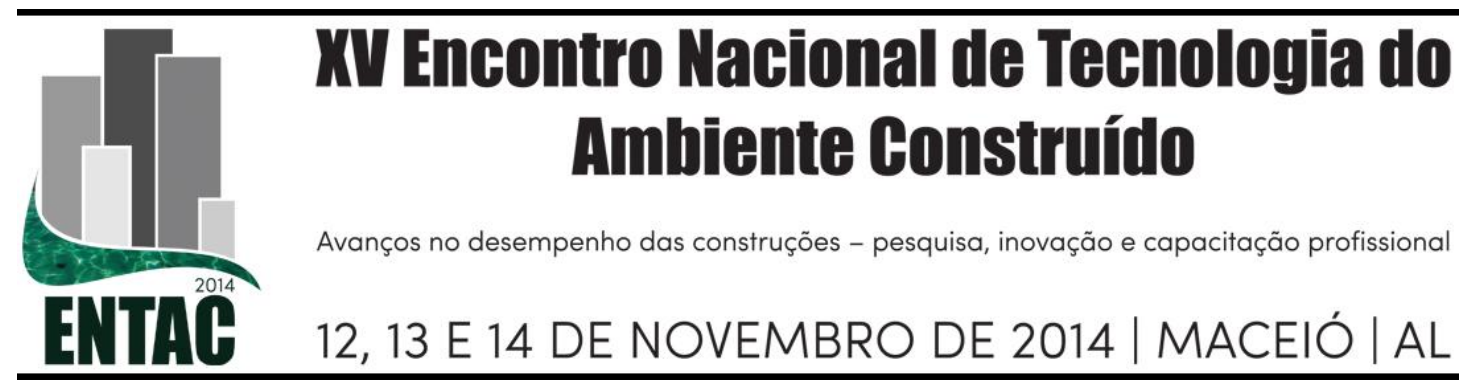

\title{
AVALIAÇÃO DE DESEMPENHO, CONFORTO TÉRMICO E IBUTG EM CONTÊINERES METÁLICOS PARA CANTEIROS DE OBRAS
}

COSTA, Débora Cristina Rosa Faria da (1); PRADO, Racine Tadeu Araujo (2)

(1) Escola Politécnica da Universidade de São Paulo, (11)3091-9170, e-mail: debora.costa@usp.br (2)

Escola Politécnica da Universidade de São Paulo, (11)3091-5147, e-mail: racine.prado@usp.br

\begin{abstract}
RESUMO
Contêineres metálicos são cada vez mais utilizados como instalações provisórias em canteiros de obras no mercado da construção civil brasileiro. Tais instalações possuem inúmeras características ambientalmente adequadas, tais como a longa durabilidade, a possibilidade de reutilização, o baixíssimo grau de geração de resíduos, dentre outras, mas seu aspecto térmico é insatisfatório. Devido a tal característica, a ocupação humana torna-se possível com climatização artificial, o que gera alta demanda por energia elétrica. A presente pesquisa tem caráter experimental, tendo sido realizadas medições de dezembro de 2013 a abril de 2014, a cada 5 minutos, com previsão de duração de um ano. O presente trabalho objetiva avaliar os parâmetros de desempenho, conforto térmico e IBUTG dos contêineres metálicos, para que se possam elaborar - futuramente - estratégias que possam diminuir o ganho térmico dos mesmos e, consequentemente, sua demanda por energia elétrica. Como resultados, constatou-se que a sensação de insatisfação com o conforto térmico ocorre de $50 \%$ a $67 \%$ do tempo medido, evidenciando a necessidade de se implantarem melhorias no aspecto térmico dos contêineres metálicos.
\end{abstract}

Palavras-chave: Contêineres metálicos, desempenho, conforto térmico, IBUTG.

\begin{abstract}
Metal containers are increasingly being used as temporary facilities on construction sites in the Brazilian construction market. Such facilities have numerous environmentally adequate characteristics such as longer durability, reusability, very low level of waste generation, among others, but their thermal characteristic is unsatisfactory. Due to that characteristic, human occupation becomes possible with air conditioning, which demands high energy. This research has an experimental character, with measurements that have been made from December 2013 to April 2014, every 5 minutes, scheduled to last one year. This article aims to evaluate metallic containers' thermal performance, thermal comfort and WBTG, to elaborate - in future - strategies that can decrease their thermal load and energy demand. As results, noted that the thermal comfort dissatisfaction happens from 50\% to 67\% of measured time, evidencing that thermal improvement is necessary.
\end{abstract}

Keywords: Metallic containers, thermal performance, thermal comfort, WBGT.

\section{INTRODUÇÃO}

Os contêineres metálicos têm sido cada vez mais utilizados em canteiros de obras, por apresentarem inúmeras vantagens sobre as demais tipologias de instalações provisórias normalmente empregadas no mercado brasileiro, como rapidez e praticidade na 
montagem, facilidade de transporte e reutilização, baixíssimo potencial de geração de resíduos.

Embora sejam ambientalmente adequadas em muitos aspectos, suas características térmicas apresentam-se extremamente insatisfatórias, o que acarreta a utilização praticamente constante de climatizadores de ar, a fim de viabilizar a ocupação humana. Este fato contribui para o aumento do consumo de energia dos contêineres comparativamente a outros sistemas construtivos utilizados como instalações provisórias em canteiros de obras. Segundo Santamouris e Kolokotsa (2013), o consumo de energia demandada pelo setor da construção civil varia conforme o país, permanecendo entre 35 a $40 \%$ da demanda mundial por energia, se consideradas as etapas de construção e o pós-ocupação. Os mesmos autores ainda afirmam que a demanda por condicionamento de ar corresponde a $15 \%$ do consumo mundial de energia.

Os contêineres metálicos utilizados como instalações provisórias de canteiros de obra diferem dos contêineres marítimos quanto ao material de composição e à espessura das paredes. Enquanto os contêineres marítimos são confeccionados em aço corten, com espessura em torno de $1,3 \mathrm{~mm}$, os contêineres para canteiros de obras são compostos predominantemente de aço galvanizado ou Galvalume ${ }^{\circledR}$, com espessura em torno de $0,65 \mathrm{~mm}$.

No setor da construção civil existe um padrão construtivo para os contêineres, relacionado principalmente às dimensões adequadas para o transporte sobre caminhão, embora haja variações de composição de materiais e dimensões, dentro da gama de produtos disponíveis no mercado brasileiro. O padrão mais utilizado apresenta altura útil de $2,50 \mathrm{~m}$, largura de $2,4 \mathrm{~m}$ e comprimento variável, frequentemente baseado na modulação de $3 \mathrm{~m}$, ou seja: há produtos com 3, 6 e $9 \mathrm{~m}$ de comprimento. São comercializados, em grande parte dos casos sem qualquer tratamento térmico nas superfícies verticais. Muitos dos produtos disponíveis no mercado possuem um forro de $2 \mathrm{~cm}$ de poliestireno expandido (EPS) junto à superfície interna da cobertura, cuja função é o isolamento térmico, acrescido de uma chapa dura de material derivado de madeira, com espessura de $2,5 \mathrm{~mm}$, para melhoria da qualidade do acabamento.

Devido à sua característica de mobilidade e flexibilidade de montagem em canteiros de obra, atrelada à logística de transporte que possibilita a rápida realocação e versatilidade no uso, os contêineres são espacialmente compactos. A limitação de suas dimensões internas leva à limitação das possibilidades de isolamento térmico, uma vez que restringe a utilização de materiais isolantes convencionais que atuem por meio da resistência térmica à transferência de calor por condução, que têm sua efetividade atrelada à espessura, além das características de condutividade térmica do material. Além disso, o material metálico com que são confeccionados tem como comportamento térmico característico a baixa inércia, o que acarreta bruscas oscilações de temperatura, além da alta condutividade térmica.

Nos canteiros de obras, são majoritariamente utilizados nas funções de apoio administrativo das obras, como nos escritórios, refeitórios, sanitários e depósitos, ou então como alojamentos para os trabalhadores. Tais características de uso foram determinantes para a compreensão de que - no caso dos contêineres - a abordagem quanto aos requisitos de conforto térmico e índices de temperatura adequados para o desempenho do trabalho faz-se necessariamente diferente, conforme o uso a que se destina, ainda que o projeto básico do contêiner seja o mesmo para os diferentes usos. 
A fim de que se possam pensar estratégias para desenvolver tecnologias capazes de diminuir o ganho térmico dos contêineres é que se objetiva, no presente trabalho, avaliar os parâmetros de desempenho, conforto térmico e IBUTG dos contêineres metálicos.

\section{FUNDAMENTAÇÃO}

Fanger (1972) desenvolveu importante trabalho para a compreensão das relações térmicas entre o corpo humano e o ambiente que o cerca. Alguns dos conceitos definidos pelo pesquisador e equipe perpassam a normatização referente à avaliação dos fenômenos térmicos, sendo amplamente difundidos. $\mathrm{O}$ presente trabalho abarca três aspectos relevantes para o conhecimento das características térmicas de tais instalações, a fim de que se possam estabelecer parâmetros para o seu uso, bem como para que se possam dimensionar sistemas tecnológicos adequados para atingir temperaturas internas próximas aos parâmetros de conforto, ou que se consiga, ao menos, diminuir a demanda por condicionamento artificial, quando da impossibilidade de atingir níveis de conforto exclusivamente por meio da ventilação natural.

\subsection{Avaliação do Desempenho Térmico}

A norma brasileira ABNT NBR 15575 - Edificações habitacionais - Desempenho (ABNT, 2013), recentemente publicada oferece parâmetros para que se avalie o desempenho térmico das envoltórias das edificações. São definidos os seguintes critérios de avaliação, para verão e inverno, para a Zona Térmica 3, onde se situa o experimento da presente pesquisa :

1) Verão:

$\mathrm{M}$ - mínimo: Temperatura interna máxima $\leq$ Temperatura externa máxima

$\mathrm{I}$ - inferior: Temperatura interna máxima $\leq$ Temperatura externa máxima $-2^{\circ} \mathrm{C}$

$\mathrm{S}$ - superior: Temperatura interna máxima $\leq$ Temperatura externa máxima $-4^{\circ} \mathrm{C}$

2) Inverno:

$\mathrm{M}$ - mínimo: Temperatura interna máxima $\geq$ Temperatura externa máxima $+3{ }^{\circ} \mathrm{C}$

$\mathrm{I}$ - inferior: Temperatura interna máxima $\geq$ Temperatura externa máxima $+5^{\circ} \mathrm{C}$

$\mathrm{S}$ - superior: Temperatura interna máxima $\geq$ Temperatura externa máxima $+7^{\circ} \mathrm{C}$

\subsection{Avaliação do Conforto Térmico}

A sensação de conforto térmico é uma combinação entre fatores pessoais e ambientais. Fanger (1972) e equipe desenvolveram uma metodologia para a avaliação dos ambientes térmicos, considerando que mesmo que as condições de conforto obtidas pela equação do conforto - também desenvolvida pelo autor - sejam satisfeitas, ainda assim haverá um percentual de usuários insatisfeitos com as condições térmicas do local. Segundo a ASHRAE 55 (2010), "conforto térmico é a condição da mente (ou estado de espírito) que expressa satisfação com as condições térmicas do ambiente". Portanto, tecnicamente admite-se que a sensação de conforto tenha um componente de subjetividade.

A partir de pesquisa realizada com 1300 pessoas submetidas a diversas situações térmicas, sob condicionamento artificial, foi desenvolvido o sistema de Voto Médio Estimado (PMV - Predicted Mean Vote), baseado em questionários respondidos pelos participantes da pesquisa. A norma ISO 7730:2005 traz diretrizes para a determinação do PMV. No entanto, o método PMV/PPD passou a ser amplamente questionado a respeito de sua validade para ambientes naturalmente ventilados, principalmente em países de clima quente. Alguns trabalhos foram desenvolvidos no sentido de aperfeiçoar o modelo de sensação térmica para situações não previstas por Fanger. Pereira e Assis 
(2010) avaliaram a adequabilidade para a realidade brasileira dos métodos propostos por Aluciems (1981), Humphreys (1978), Nicol e Humphreys (2002) e DeDear e Brager (2002), afirmando que o modelo adaptativo proposto pelos últimos pesquisadores possibilita proximidade entre os parâmetros de conforto estabelecidos e a realidade dos diversos climas brasileiros. Dessa forma, optou-se por utilizar para a análise dos padrões de conforto a Metodologia do Conforto Adaptativo proposta por DeDear e Brager (2002), que passou a integrar a norma ASHRAE 55, no ano de 2004.

DeDear e Brager (2002) consideram que as sensações térmicas sofrem influência da expectativa que se tem sobre o clima local. Assim, os parâmetros de conforto variariam conforme o contexto em que se inserem. O método se utiliza dos valores de Temperatura de Bulbo Seco para o ambiente externo e dos valores de Temperatura Operativa, obtidos por meio da Equação 1:

$$
T o=a * T a+(1-a) * T r
$$

com :

a - constante, a ser obtida pela Tabela 5 ;

$\mathrm{Ta}$ - temperatura de bulbo seco ou temperatura do ar ambiente $\left({ }^{\circ} \mathrm{C}\right)$;

$\mathrm{Tr}$ - temperatura radiante média $\left({ }^{\circ} \mathrm{C}\right)$;

Tabela 1- Valores para a constante $a$ em função da velocidade do ar

\begin{tabular}{|c|c|c|c|}
\hline $\mathrm{V} \mathrm{a}(\mathrm{m} / \mathrm{s})$ & $0-0,2$ & $0,2-0,6$ & $0,6-1,0$ \\
\hline $\mathrm{a}$ & 0,5 & 0,6 & 0,7 \\
\hline
\end{tabular}

Fonte:ASHRAE Fundamentals (2010)

O Modelo Adaptativo estabelece uma faixa onde se localiza a sensação de conforto térmico que compreende a satisfação de até $90 \%$ dos usuários, e duas faixas para valores acima e abaixo dessa, cujo percentual de satisfeitos atinge os $80 \%$, conforme Figura 1.

\section{Figura 1- Intervalo para Temperaturas Operativas aceitáveis para edificações naturalmente ventiladas}

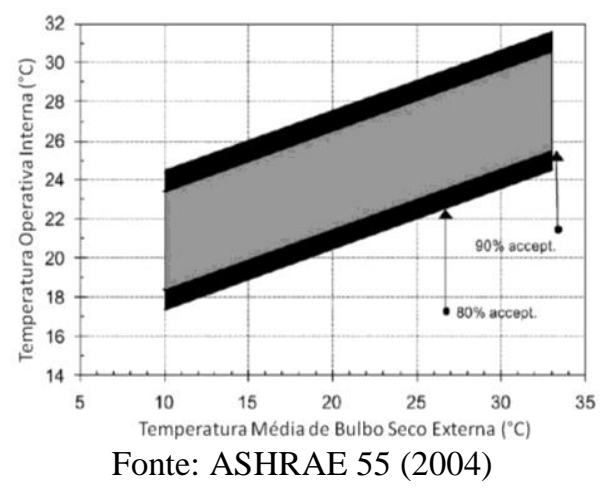

\subsection{Avaliação do estresse térmico (IBUTG)}

No Brasil, o Ministério do Trabalho e Emprego utiliza a Norma Regulamentadora $\mathrm{n}^{\circ} 15$ - Atividades e Operações Insalubres (BRASIL, 1978), baseada na norma ISO 7726:1998 para a fiscalização das condições térmicas no ambiente de trabalho. Eu seu Anexo III - Limites de tolerância para exposição ao calor, a norma brasileira oferece um modelo de avaliação de ambientes quentes, denominado IBUTG - Índice de Bulbo 
Úmido Temperatura de Globo, baseado na ISO 7243:1989. Os valores do índice IBUTG são obtidos por meio da Equação 2:

$$
I B U T G=0,7 T b n+0,3 T g
$$

Onde:

Tbn - temperatura de bulbo úmido à ventilação natural $\left({ }^{\circ} \mathrm{C}\right)$

$\mathrm{Tg}$ - temperatura de globo $\left({ }^{\circ} \mathrm{C}\right)$

A Tabela 2 fornece o tipo de regime de trabalho permitido sob condições de estresse térmico, impondo restrições à jornada dos trabalhadores submetidos a tais condições.

Tabela 2- Regime de trabalho permitido de acordo com os valores calculados de IBUTG

\begin{tabular}{|l|c|}
\hline \multicolumn{1}{|c|}{$\begin{array}{c}\text { REGIME DE TRABALHO INTERMITENTE COM DESCANSO NO PRÓPRIO LOCAL DE } \\
\text { TRABALHO (por hora) }\end{array}$} & ATIVIDADE LEVE \\
\hline trabalho contínuo & até $30^{\circ} \mathrm{C}$ \\
\hline 45 minutos de trabalho/15 minutos de descanso & 30,1 a $30,5^{\circ} \mathrm{C}$ \\
\hline 30 minutos de trabalho/30 minutos de descanso & 30,7 a $31,4^{\circ} \mathrm{C}$ \\
\hline 15 minutos de trabalho/45 minutos de descanso & 31,5 a $32,2^{\circ} \mathrm{C}$ \\
\hline não é permitido o trabalho sem a adoção de medidas adequadas de controle & acima de $32,2^{\circ} \mathrm{C}$ \\
\hline \multicolumn{2}{|c}{ Fonte: adaptado de NR-15 (BRASIL, MTE, 1978$)$}
\end{tabular}

\section{MATERIAIS E MÉTODOS}

O experimento foi montado no município de Mairinque-SP, latitude $23^{\circ} 32^{\prime} 45^{\prime \prime}$ Sul e longitude $47^{\circ} 11^{\prime} 00^{\prime \prime}$ Oeste, altitude de $850 \mathrm{~m}$, situado na ZB 3, segundo o Zoneamento Bioclimático Brasileiro, conforme a ABNT NBR15220-3 (2013).

\subsection{Caracterização do modelo}

A pesquisa foi realizada por meio de medições térmicas, utilizando-se um contêiner metálico, confeccionado em aço Galvalume ${ }^{\circledR}$, com $3 \mathrm{~m}$ de comprimento, 2,4m de largura e $2,5 \mathrm{~m}$ de altura, piso em compensado de madeira de $2 \mathrm{~cm}$ de espessura, disposto a $23 \mathrm{~cm}$ de altura do solo, contendo uma janela nas dimensões $1 \times 1 \mathrm{~m}$ e uma porta de $0,8 \times 2,1 \mathrm{~m}$ do mesmo material da composição.

\subsection{Posicionamento}

O contêiner foi disposto de modo a receber a maior quantidade de irradiação solar possível, tendo sido posicionado com a superfície cega de maior área voltada para o Norte, locado - a partir de estudos realizados com cartas solares - de modo a evitar sombreamento durante a maior parte do dia, ao longo das quatro estações, conforme Figura 2. 
Figura 2- Esquema de montagem e locação do experimento

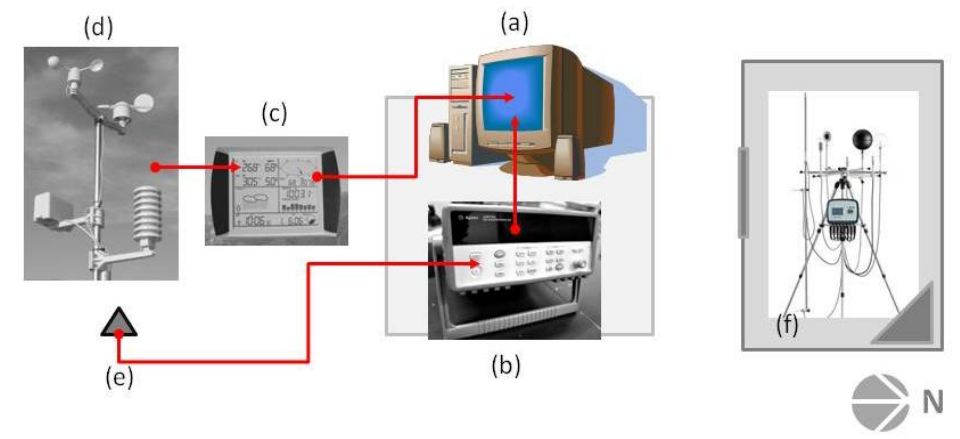

\subsection{Instrumentação e medições}

Para o monitoramento das características climáticas locais foi instalada a estação meteorológica ITWH-1080 (d), um termopar tipo T (liga $\mathrm{Cu} / \mathrm{Cu}-\mathrm{Ni}$, cobre-constantan (e), conectado ao datalogger (b), recomendado para medições de temperaturas dentro da faixa de $-270^{\circ} \mathrm{C}$ a $370^{\circ} \mathrm{C}$ ) envolvido em fita aluminizada, disposto a 3,5m de altura para a medição da temperatura de bulbo seco externa ao contêiner. Além da instrumentação descrita, a cadeia de medições é composta por um piranômetro modelo "Black and White" da marca Eppley para as medições de irradiação solar total, além de 36 termopares que realizam medições constantes de temperaturas superficiais $\mathrm{e}$ temperaturas de globo, que apresentam resultados relevantes para desdobramentos futuros da presente pesquisa.

Para a realização das medições das temperaturas internas ao contêiner, utilizou-se o confortímetro Delta OHM, Modelo HD 32.1(f), com os seguintes sensores: termômetro de globo, termômetro de bulbo seco, termômetro de bulbo úmido a ventilação natural e anemômetro a fio quente, para a medição da velocidade do ar. Todas as medições foram realizadas conforme as recomendações da norma ISO 7726:1998. Os valores de IBUTG fornecidos pelo equipamento são obtidos a partir dos valores medidos de temperatura de globo e temperatura de bulbo úmido, e posteriormente processados, conforme a Equação 3, pelo software do equipamento.

\subsection{Método de análise}

Considerando a classificação dos contêineres segundo o uso a que se destinam no canteiro de obras, optou-se por realizar as análises no presente trabalho em dois grupos:

- Contêineres destinados ao trabalho (escritórios): utilizados para as atividades diurnas desenvolvidas no canteiro de obras. São analisados quanto às exigências da Norma Regulamentadora $\mathrm{n}^{\circ} 15$, do Ministério do Trabalho e Emprego (BRASIL, 1978), que se utiliza da medição de Índice de Bulbo Úmido e Temperatura de Globo (IBUTG). Considera-se que o trabalho nos canteiros será realizado no horário comercial, das 8:00 às 18:00, predominantemente em atividades leves, como as desenvolvidas em escritório. Portanto, as análises de IBUTG serão realizadas para o horário descrito;

- Contêineres destinados ao repouso (alojamentos): são analisados quanto aos parâmetros de conforto do método adaptativo constante da ASHRAE 55 (2004). Considera-se, para tanto, a necessidade de avaliar o ambiente durante as 24 h diárias, já que existe a possibilidade de permanência nos alojamentos ao longo do dia e, principalmente aos finais de semana ou dias de folga, quando há impossibilidade de retorno dos operários às suas residências. 
As duas categorias de contêineres - para trabalho e para repouso - são analisadas segundo a norma ABNT NBR 15575 (ABNT, 2013) quanto ao desempenho térmico.

\section{RESULTADOS E DISCUSSÃO}

As medições no contêiner metálico foram realizadas com o confortímetro nas datas da Tabela 3-Datas em que foram realizadas as medições, de acordo com a disponibilidade do equipamento.

Tabela 3-Datas em que foram realizadas as medições com o confortímetro

\begin{tabular}{|c|c|c|c|c|c|}
\hline mês & dezembro/2013 & janeiro/2014 & fevereiro/2014 & março/2014 & abril/2014 \\
\hline dias & 27 a 30 & 6 a 10 & 3 a 15 & 10 a 17 & 1 a 12 \\
\hline
\end{tabular}

\subsection{Avaliação de estresse térmico (Índice IBUTG)}

A medição dos valores de IBUTG determina a possibilidade de que o ambiente seja utilizado para o trabalho ininterrupto, quando não se encontra sob temperaturas que levem ao estresse térmico, ou com redução de jornada de trabalho, caso as temperaturas obtidas a partir da equação que considera a temperatura de bulbo úmido e a temperatura de globo, superem os $30^{\circ} \mathrm{C}$.

Os valores médios mensais obtidos nas medições realizadas no contêiner metálico encontram-se na Figura 3.

Figura 3- IBUTG para o contêiner metálico

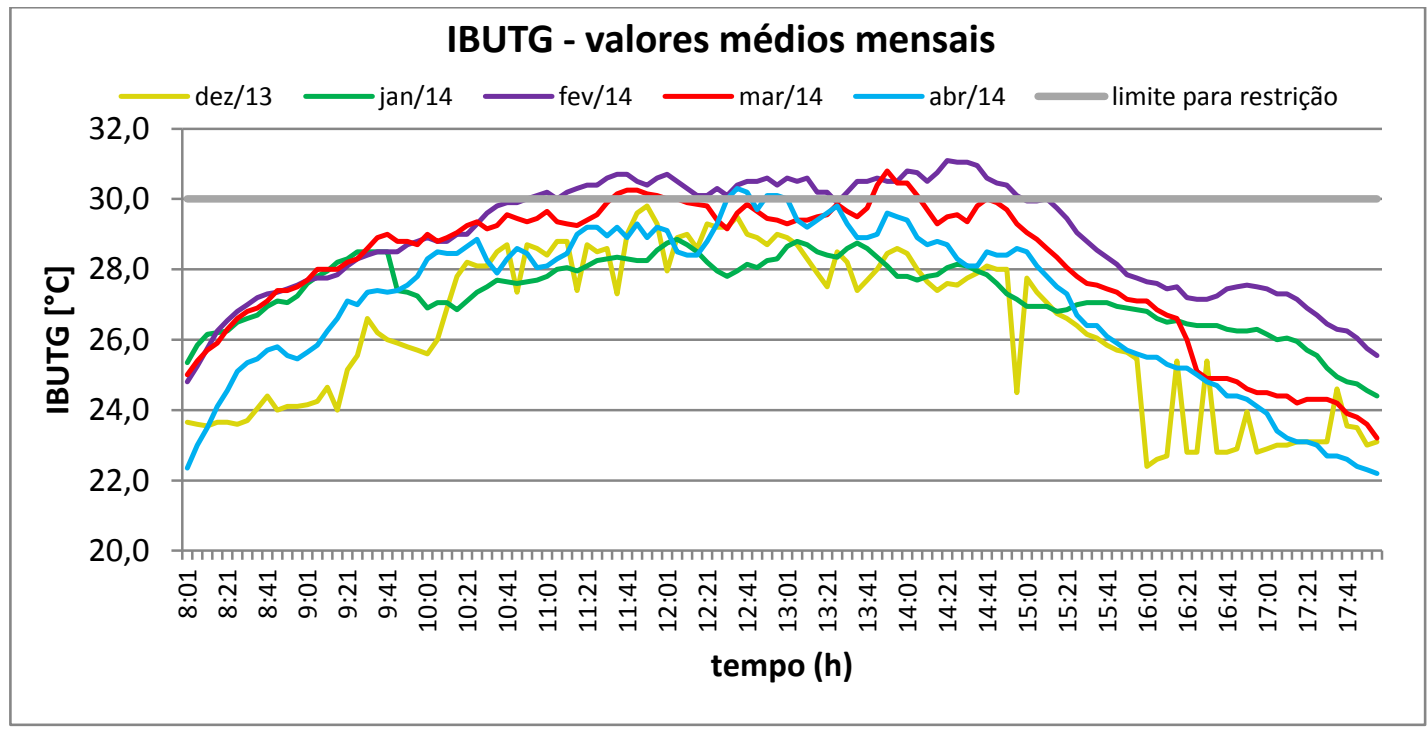

De acordo com a NR-15, considerando a realização de trabalho leve, as medições evidenciam situações de estresse térmico no interior do contêiner metálico, quando mantido sem tratamento térmico e ventilado naturalmente. Observa-se, pela Figura 4, que nos meses de fevereiro, março e abril há necessidade de aplicação das restrições quanto à jornada de trabalho, como determinado pela norma regulamentadora.

Figura 4- número de horas com valores de IBUTG acima de $30^{\circ} \mathrm{C}$ (média mensal) 


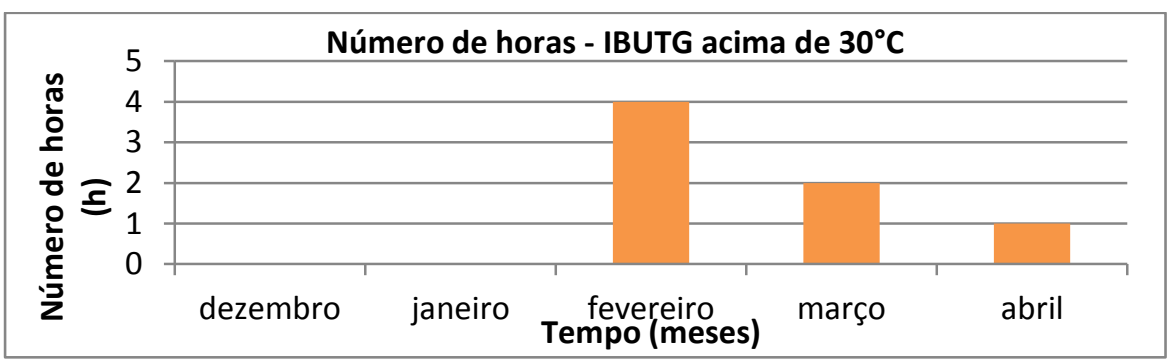

Dos valores médios mensais de IBUTG que ultrapassam o limite de $30^{\circ} \mathrm{C}, 82 \%$ incluem-se na faixa entre $30,1^{\circ} \mathrm{C}$ e $30,5^{\circ} \mathrm{C}$, que determina que haja descanso de 15 minutos a cada hora de trabalho, ao passo que $18 \%$ se enquadram na faixa que vai de $30,7^{\circ} \mathrm{C}$ a $31,4^{\circ} \mathrm{C}$, cujo regime de trabalho é determinado por descanso de meia hora a cada hora trabalhada. Não foram obtidos resultados superiores a essa faixa.

\subsection{Conforto Térmico}

As Temperaturas Operativas Médias medidas nos meses de dezembro de 2013 a abril de 2014 indicam que durante o verão há grande amplitude térmica no interior do contêiner, partindo de temperaturas inferiores aos limites de conforto no período noturno e atingindo temperaturas que superam largamente os limites de conforto para o calor, conforme se observa na Figura 5.

Figura 5- Temperatura operativa média nos meses medidos

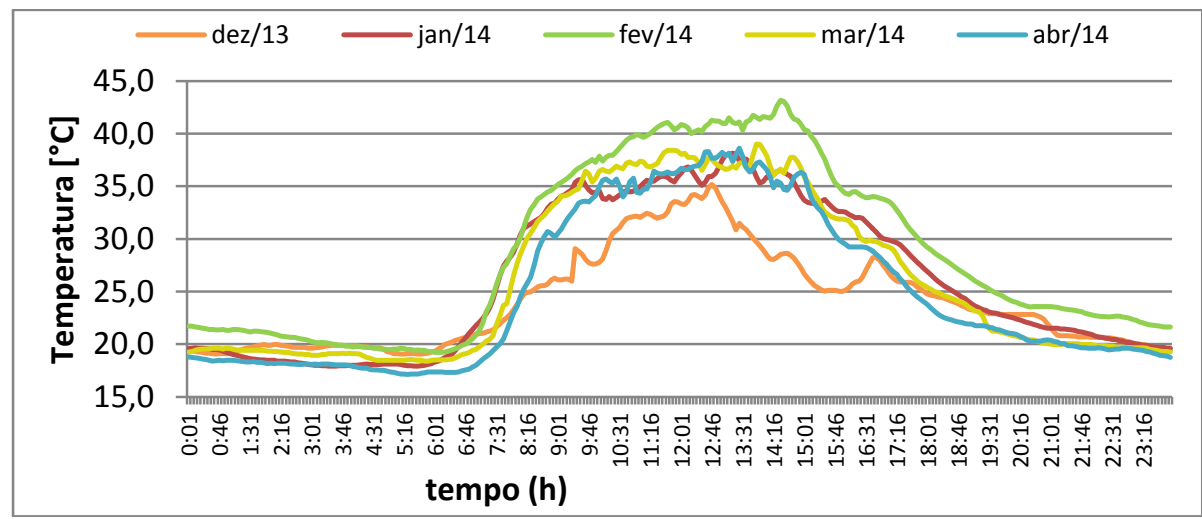

Nota-se que no período noturno, as temperaturas operativas atingem valores baixos, demandando aumento do fator de isolamento térmico da roupa ou mesmo certo tipo de aquecimento no interior do contêiner. Durante o dia, os valores de temperaturas tendem a acompanhar a intensidade da irradiação solar, atingindo o pico de temperatura aproximadamente ao meio dia, horário em que a irradiação também alcança os maiores valores, devido ao ângulo de incidência entre o sol e a reta normal à superfície horizontal de cobertura ser pequeno.

A avaliação das medições quanto à sensação térmica evidencia, conforme nota-se pela Figura 6, a predominância de valores situados fora dos limites de sensação de conforto, tanto atingindo temperaturas mais altas, quanto mais baixas - estas exclusivamente no período noturno, nas medições realizadas até o presente.

A ASHRAE 55 (2004) determina que sejam estabelecidos parâmetros de conforto para temperaturas operativas situadas dentro do intervalo de $10^{\circ} \mathrm{C}$ a $33,5^{\circ} \mathrm{C}$ para a ventilação natural, conforme se observa pelas linhas de limites constantes da Figura 6. Temperaturas operativas que superem os $33,5^{\circ} \mathrm{C}$ estariam, portanto, fora do limite de conforto. 
Figura 6 - Sensação Térmica segundo o modelo de conforto adaptativo da

ASHRAE 55 (2004)

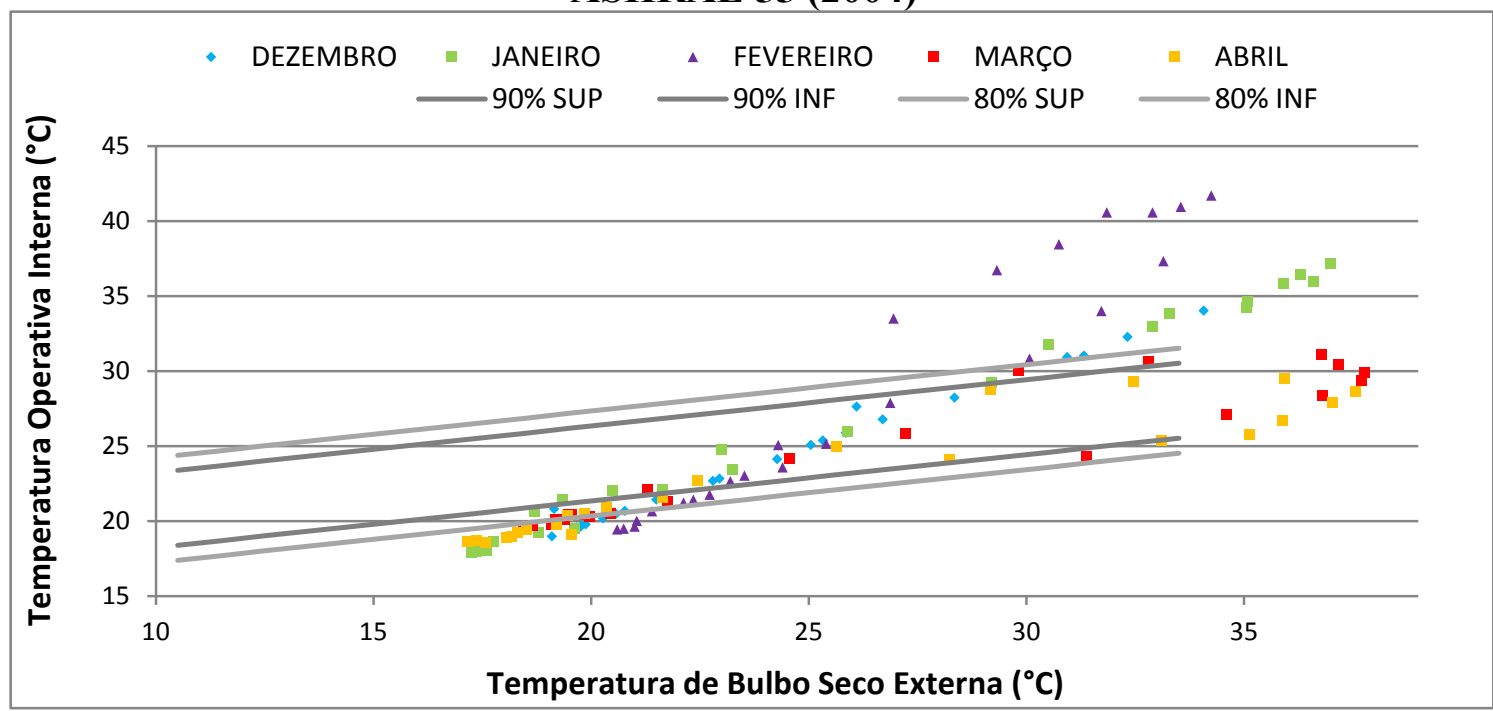

Observa-se que o mês no qual há maior predominância de pontos situados dentro da zona mais próxima ao conforto é dezembro, ao passo que fevereiro é o mês com maior percentual de insatisfação devido às altas temperaturas e abril o mês com maior percentual de insatisfação devido às baixas temperaturas, conforme a Erro! Fonte de referência não encontrada..

Tabela 4- Percentual de satisfação quanto à sensação térmica

\begin{tabular}{|l|c|c|c|c|c|}
\hline sensação térmica & dezembro & janeiro & fevereiro & março & abril \\
\hline abaixo do limite inferior 80\% satisfeitos & 33,3 & 29,2 & 20,8 & 29,2 & 37,5 \\
\hline dentro 80\% satisfeitos inferior & 12,5 & 4,2 & 12,5 & 16,7 & 20,8 \\
\hline dentro 90\% satisfeitos & 37,5 & 25,0 & 25,0 & 16,7 & 20,8 \\
\hline dentro 80\% satisfeitos superior & 0,0 & 4,2 & 0,0 & 8,3 & 0,0 \\
\hline abaixo do limite superior 80\% satisfeitos & 16,7 & 37,5 & 41,7 & 29,2 & 20,8 \\
\hline total de ocorrências fora dos limites de satisfação & 50 & 66,7 & 62,5 & 58,3 & 58,3 \\
\hline
\end{tabular}

Na Tabela 4 foram contabilizados os pontos de medição correspondentes a cada mês, de acordo com sua posição no gráfico da Figura 6, evidenciando que há predominância de ocorrências situadas fora dos parâmetros de conforto, ou seja, localizadas acima ou abaixo dos limites superior e inferior de $80 \%$ de satisfação, conforme se observa na última linha da Tabela 4.

\subsection{Desempenho}

As medições apontam a intensidade dos fenômenos de transferência de calor ocorridos na envoltória do contêiner. Observando-se os gráficos formulados para os meses de dezembro a abril - com base nas medições realizadas até a presente data - pode-se constatar que nos períodos noturnos a envoltória realiza trocas negativas com o ambiente externo, isto é, perde calor, enquanto durante o dia absorve e acumula calor, atingindo temperaturas de bulbo seco internas que superam as mesmas temperaturas medidas no ambiente externo. Segundo a NBR 15575: 2013, para que se atinja o critério mínimo de desempenho na envoltória, a temperatura do ar interno deve ser, no máximo, igual à temperatura do ar medida no ambiente externo. 
Figura 7- TBS externo x TBS interno para fevereiro (média mensal)

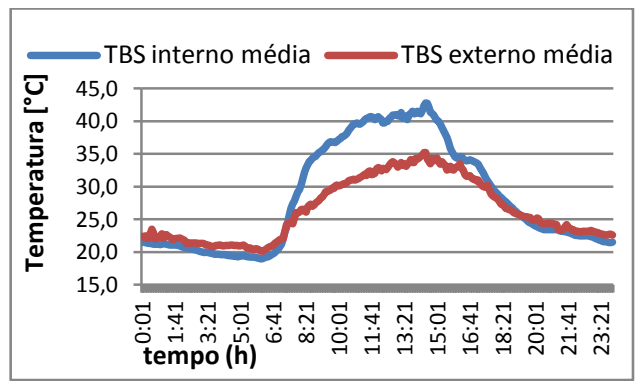

Figura 8- Número de horas cujo desempenho permanece abaixo do padrão mínimo (a partir da média mensal)

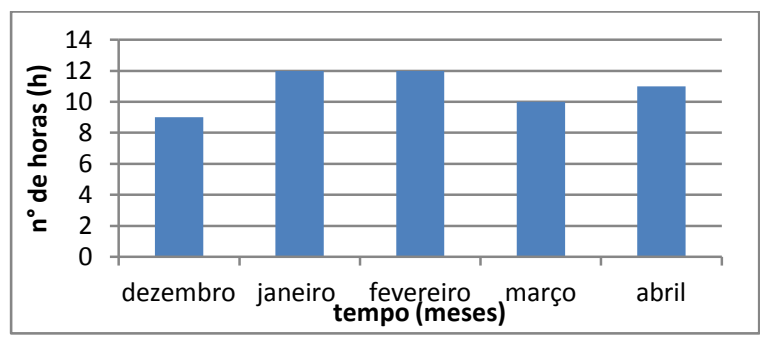

\section{CONCLUSÕES}

A partir das medições realizadas pode-se constatar que a envoltória dos contêineres metálicos, sem tratamento térmico, não oferece resistência térmica suficiente para diminuir as trocas térmicas com o ambiente, tanto para as temperaturas frias, quanto para as quentes. As instalações confeccionadas com o Galvalume ${ }^{\circledR}$ permanecem em grande parte do tempo sob altas temperaturas, apesar de terem sido constatados poucos episódios de estresse térmico. Mesmo tendo sido observados somente alguns episódios de estresse térmico, deve-se notar que a restrição de jornada de trabalho determinada pela NR-15 pode trazer impactos que poderiam ser evitados com o adequado tratamento térmico da envoltória dos contêineres. Ainda assim, as temperaturas atingidas permanecem predominantemente em zona de desconforto térmico, já que o percentual de pontos medidos fora dos pontos de conforto vai de $50 \%$ em dezembro a $66,7 \%$ em fevereiro, e os resultados obtidos nas medições para avaliação do estresse térmico sejam poucos, se comparados à totalidade das medições.

As análises de desempenho evidenciam tal constatação. A envoltória oferece resistência muito baixa à absorção da radiação, e de modo muito semelhante à condução do calor, sendo necessário, para amenizar tal situação, que os parâmetros de resistência térmica fossem otimizados. Caminhos viáveis para a obtenção de melhorias térmicas seriam a diminuição do coeficiente de condutividade térmica por meio da inserção de novos materiais, além da alteração das características relacionadas à absortividade e emissividade do material.

\section{REFERÊNCIAS BIBLIOGRÁFICAS}

ABNT - ASSOCIAÇÃO BRASILEIRA DE NORMAS TÉCNICAS. NBR 15220-3. Desempenho térmico de edificações - Parte 3: Zoneamento bioclimático brasileiro e diretrizes construtivas para habitações unifamiliares de interesse social. 2005.

ABNT NBR 15575-1 - Edificações Habitacionais - Desempenho Parte 1: Requisitos Gerais. . 2013.

AMERICAN SOCIETY OF HEATING, REFRIGERATING AND AIR-CONDITIONING ENGINEERS, INC. ASHRAE STANDART 55-2010. Thermal Environmental Conditions for Human Occupancy. . 2010.

BRASIL, MINISTÉRIO DO TRABALHO E EMPREGO. NR 15 - ATIVIDADES E OPERAÇÕES INSALUBRES - Anexo III-Limites de tolerância para exposição ao calor. 1978.

DEAR, R. J. DE; BRAGER, G. S. Thermal comfort in naturally ventilated buildings: revisions to ASHRAE Standard 55. Energy and Buildings, v. 34, n. 6, p. 549-561, jul. 2002.

FANGER, P.O. Thermal comfort: analysis and applications in environmental engineering. New York: McGraw-Hill, 1972. 
INTERNATIONAL ORGANIZATION FOR STANDARDIZATION. ISO 7726:1998 Ergonomics of the thermal environment -Instruments for measuring physical quantities. . Genève 1998.

PEREIRA, I.M.; ASSIS, E.S. Avaliação de modelos de índices adaptativos para uso no projeto arquitetônico bioclimático. Ambiente Construído, v. 10, n. n.1, p. 31-51, mar. 2010.

SANTAMOURIS, M.; KOLOKOTSA, D. Passive cooling dissipation techniques for buildings and other structures: The state of the art. Energy and Buildings, v. 57, p. 74-94, fev. 2013.

\section{AGRADECIMENTOS}

À FINEP, Rede CANTECHIS, à CAPES pelo apoio recebido e à Fundação de Amparo à Pesquisa do Estado de São Paulo (FAPESP), processo nº 2014/16362-1, pelo apoio na divulgação da pesquisa. 